\title{
SOBRE LA FUNDACIÓN DEL ESPACIO ANALÍTICO: ACTUALIDAD DEL LEGADO DE SIGMUND FREUD
}

\author{
ABOUT THE FOUNDATION OF THE ANALYTICAL REALM: \\ UPDATED SIGMUND FREUD'S LEGACY.
}

\author{
Laura Veríssimo de Posadas \\ Universidad Católica del Uruguay, Uruguay
}

\begin{abstract}
Resumen: El trabajo se propone reflexionar sobre las condiciones que hacen posible un proceso psicoanalítico, desde la mirada que nos legara Sigmund Freud. Se discurre acerca de la creación de un espacio, delimitado por un encuadre, al que se compara con la escena onírica, con sus reglas propias y, a la vez, como ella, permeado por la realidad externa. Es allí que la función analítica puede ejercerse apoyada, también, en la atención flotante y la regla de abstinencia que siguen considerándose pilares fundamentales del método. Desde estas afirmaciones se toma posición en los debates actuales respecto a la práctica analítica. Una breve viñeta ilustra algunas de las ideas planteadas.
\end{abstract}

Palabras claves: Proceso psicoanalítico; Regla de abstinencia; Atención flotante; Transferencia; Inconsciente.

\begin{abstract}
The aim of this paper is to reflect upon the conditions that make possible the psychoanalytical process, about the Sigmund Freud legacy. It underlines the creation of a framework with its own rules but in touch with the real world. It is there that the analytical function can be deployed according to suspended attention and abstinence rule, both considered as basic to this method. A brief clinical situation illustrates some of the lines of thought of this paper.
\end{abstract}

Key Words: Psychoanalitical process; Rule of abstinence; Suspended attention; Transference; Unconcious

\section{INTRODUCCIÓN}

El psicoanálisis, desde sus orígenes, navegó entre Escila y Caribdis: entre la Escila de las exigencias positivistas y la Caribdis del ideal Romántico. Gracias a ambas influencias nace. De la primera conserva la permanente revisión de sus postulados y sus instrumentos. De la segunda el impulso a romper los marcos de la lógica aristotélica para explorar "las regiones infernales" (Freud, 1990 a) regidas por los procesos primarios, leyes que Freud postula para dar cuenta del modo de funcionamiento del Inconsciente (Freud, 1900 a). El psicoanálisis solo logra preservar este su objeto de estudio (el inconsciente) si, moviéndose entre ellas, no se deja atrapar por ninguna de esas tentaciones que lo acosan.

En el horizonte actual de la pluralidad de escuelas del movimiento psicoanalítico ambos riesgos, en mi opinión, están representados, por un lado, por la pretensión de cientificidad de la investigación empírica de resultados de la experiencia psicoanalítica y por otro, por las pretensiones integradoras que desembocan en un sincretismo, tan propio de nuestra época, que llevan a la pérdida de rigor conceptual, a la babelización y en ocasiones a la distorsión de los conceptos. Las repercusiones de esta situación son inevitables en la clínica.

El presente trabajo intenta trasmitir una toma de posición: la de que los conceptos fundamentales -sexualidad infantil, conflicto, inconciente, transferencia- no solo conservan su vigencia sino que siguen siendo los instrumentos imprescindibles para dar cuenta del encuentro $y$ el proceso entre analista y paciente. Ellos son los que delimitan el campo propio del psicoanálisis, discriminándolo de otros abordajes terapéuticos que, legítimamente, operan con otros instrumentos y desde otras conceptual-

Correspondencia: Prof. Lic. Laura Veríssimo de Posadas, Facultad de Psicología de la Universidad Catòlica del Uruguay, Montevideo, Uruguay. Correo Electrónico: Iverisimo@adinet.com.uy. 
izaciones teóricas.

TEORÍA Y PRÁCTICA

DEL PSICOANÁLISIS

La posibilidad de despliegue de un proceso psicoanalítico se apoya en la fundación de un espacio (Laplanche,1992 b.) donde la palabra del paciente pueda ser escuchada y sostenida. Palabra del otro, palabra ajena, que me descoloca respecto a mis roles y modos habituales de intercambio(Freud, $1913 \mathrm{f}$ ). Palabra del otro que convoca lo que no conozco de mí y que viene de lo desconocido de quien habla y de quien escucha.

Se crea así un espacio que también es "otro" que el de la realidad cotidiana y compartida un espacio en el cual dos, marcados por lo desconocido de cada uno, se encuentran porque uno de ellos demanda ser escuchado y recurre a alguien que está dispuesto a poner en suspenso los deseos propios, el propio saber, para escuchar lo más singular de quien le pide ayuda.

A través de un conjunto de gestos instauradores (Freud, 1913 f; Laplanche, 1992 b) buscamos establecer las condiciones para que la función del analista pueda ser posible. Con ese objetivo enmarcamos con elementos estables (horarios, honorarios, frecuencia de las sesiones) un espacio que, en algunos aspectos, evoca la "otra escena" onírica (Freud, 1900 a): como en ésta la llave de la motilidad permanece cerrada y los principios lógicos, con que habitualmente nos manejamos, cesan a favor de otra lógica, la de los procesos primarios. Como sucede en el sueño el deslizamiento asociativo conduce a productos inesperados, quiebres del discurso, ocurrencias que "caen" (einfall, es la palabra que usa; Freud,1913 f) con su efecto de sorpresa tanto para quien lo enuncia como para quien lo escucha. Es en lo nimio, lo dicho al pasar o en el error, que algo de la verdad del sujeto puede surgir. Esta palabra en estado naciente, surgiendo, dicha a medias, sin saber lo que se dice, es la materia prima con la que el analista trabaja con su paciente.

Para hacerla posible escucha en atención flotante (Freud, 1912 d) y en un doble movimiento: de acercamiento, de identificación y otro de rescate, de desidentificación (Baranger, 1994). La función analítica nos exige clivages operativos gracias a los cuales dejamos de lado nuestros afanes y preocupaciones inmediatas sin que ello implique despojarnos de nosotros mismos. Por el contrario, nos acercamos al paciente con todo lo que somos: nuestro modo de ser, nuestro estilo de comunicación, nuestra historia personal, nuestras preferencias teóricas. Si bien todo ello es puesto en suspenso jugará su parte en la historia que entre dos escribiremos.

Tal vez sea por esa fatal situación y porque la transferencia es la producción del Inconsciente por excelencia que Freud (1912, g 1914 d) es categórico en cuanto a la regla de abstinencia. Regla que implica un "estado de privación" tanto para el paciente como para el analista, frustración del paciente y rehusamiento del analista (Laplanche, 1987a), tanto respecto a la acción como al juicio, tanto respecto a la prescripción como a fines determinados de antemano. "Nos negamos de manera terminante, dice Freud (1919 i), a hacer del paciente que se pone en nuestras manos en busca de auxilio un patrimonio personal, a plasmar su destino por él, a imponerle nuestros ideales y, con la arrogancia del creador, a complacernos en nuestra obra luego de haberlo formado a nuestra imagen y semejanza."

Es esta posición de abstinencia lo que nos distingue de otras prácticas psicoterapéuticas.

En los debates actuales, entre distintas escuelas psicoanalíticas (Paniagua, 1997) nos ubicamos, firmemente, entre quienes sostienen la limitación del actuar por parte del analista y tomamos distancia de quienes proponen "autorevelaciones" al paciente, es decir, explicitaciones de las respuestas emocionales del analista en actuaciones, en una "puesta en escena contra-transferencia I"(Renik,1993).

Esta toma de posición se apoya en la búsqueda de las mejores condiciones desde las que podamos seguir las cadenas de sentido y descubrir, a través de las producciones del paciente, de sus personajes, de su modo peculiar de decir y de callar, de actuar y de somatizar, de mostrar y ocultar, la "otra escena" (Freud, 1900 a): la de sus amores y odios infantiles, sus puntos de fijación (Freud, 1905 b) y de insistencia, la de su desamparo y sus traumas, la de las marcas que hacen de cada uno quien es.

La emergencia de estos "titanes inmortales" (Freud, 1900 a), los deseos infantiles reprimidos, constituye "material altamente explosivo", advierte Freud (1914 g). Por esto el cuidado del paciente requiere, de parte del analista, el desarrollo de la "función continente 
de la personalidad" (Bion, 1962) lo que implica metabolizar afectos intensos, recibir proyecciones sin actuarlas, conservar en nuestro espacio psíquico todo lo que viene del paciente, sin expulsarlo, porque el mejor destino de ese material, intensamente cargado, es que sea pensado, procesado por nuestro inconciente y retorne a través de nuestras asociaciones (a veces de nuestros sueños) hasta alcanzar al paciente transformado en interpretación.

Si logramos posicionarnos de esa función se producen, en las situaciones más favorables, efectos que favorecen el trabajo de análisis: el paciente aprende a reconocer ese espacio y esa relación como radicalmente heterogéneos a todos los que conoce y allí focaliza su malestar, a la vez que ubica sus esperanzas.

Pero ocurre algo más; empieza a "catectizar la actividad de representación" (Aulagnier, 1988 a). Cuando Freud (1905 b) analiza, en su trabajo sobre el chiste, las fuentes del placer que éste procura, descubre, entre otras "el afán de los hombres de obtener placer de sus procesos de pensamiento" Me parece algo que rara vez se menciona y que no se debe menospreciar en nuestra práctica. Esa ganancia de placer tiene enorme potencial creativo y es motor del trabajo de análisis. Junto con el descubrimiento de un espacio que, como decíamos más arriba, no sólo es nuevo sino tan propio ("lo más mío que tengo", decía un paciente) contribuye a un estrechamiento de la alianza con el terapeuta (Freud, 1913 f). El espacio-tiempo de la sesión constituye así "un teatro donde el analista se transforma en todas las personas de alrededor"(idem), donde ocurre algo del orden del jugar, porque se juega con representaciones, con presencia y ausencia, sentido y afecto, y donde las "experiencias de verdad", parciales pero encarnadas en la transferencia, van construyendo otra historia.

Para que la historia se despliegue en su actualidad (porque la historia no es algo que fue sino un relato que va haciéndose) el encuadre (Freud,1913 f; Laplanche, 1987 a.) tiene que cumplir su función de contención: la regularidad del tiempo, la constancia inalterable del ambiente y de la atención del terapeuta son "holding" y envoltura de un psiquismo que se arriesga a una aventura de reestructuración.

Una breve viñeta me ayuda a ilustrar algunas de las ideas planteadas. La paciente comienza diciendo que, antes de salir para su sesión, comentaban en su oficina el crimen del Tigre.
Yo veo que da por hecho que conozco el caso y comenta que a ella no le impactó demasiado, lo cual me parece llamativo en relación a su sensibilidad habitualmente agudizada. Lo que me interesa es el relato que ella haga del hecho. Por eso renuncio a todo mi saber conciente sobre mi paciente, así como sobre el hecho policial y los sentimientos que me suscita. Le pregunto, con aire de desinformada: “¿cómo es eso?”

Paciente:

"Dos jóvenes se amaban tanto que él se perseguía con que ella lo engañaba. Ella le pedía confianza, respeto... están sus cartas, su diario... a veces se golpeaban hasta que él, enloquecido, le dio 113 puñaladas y no sé cuántos golpes...la besaba y le pegaba, la acariciaba y le pegaba...."

Decía que me interesa su relato, lo que lo singulariza, lo que me señala del paciente en relación a sus puntos de fijación libidinal (Freud, 1905 b), a sus identificaciones (Freud, 1921 j), sus fantasías, a sus circuitos repetitivos y/o sus posibilidades de articulación como sujeto deseante (Lacan,1960)

En esta paciente el núcleo paranoide (Freud, 1922 k) tenía visos de un cuadro delirante al comienzo de su análisis. En el relato, a través de la sintaxis "se amaban tanto que...", se atisba que los celos patológicos (con su infraestructura de desconfianza y proyección) hubieran sido una consecuencia inevitable del amor. Intenta defenderse diciendo que a ella no le impactó, siendo que sus propios desbordes violentos la han asustado mucho y han sido motivo de una exhaustiva indagación analítica. A su vez, destaca esa conjunción golpes - caricias ( dolorplacer ), verdadero tópico de insistencia en esta paciente. Esta conjunción reaparece, una y otra vez, en sus producciones del inconsciente: tanto en sus sueños, en el movimiento de sus asociaciones, en la fuente de sus actuaciones, como lo hace ahora en su singular manera de armar la historia a partir de un hecho de la crónica policial. Lo que nos interesa en el análisis no es el hecho crudo (que es incognoscible) sino el relato, siempre altamente singular, siempre producto transaccional del deseo inconciente y las defensas (Freud,1915 h); ¿cómo no recordar aquí la brillante Rashomon de Akira Kurosawa?.

Concluiría con algo de Piera Aulagnier (1988 a) que da cuenta de aquello que, en lo personal, no dejo de desear cada vez que, con otro, inauguramos un nuevo espacio de análisis: 
"que el sujeto pueda, una vez terminado su itinerario analítico, poner, aquello que adquirió en la experiencia vivida, al servicio de objetivos elegidos siempre en función de la singularidad de su problemática, de su alquimia psíquica, de su historia. De objetivos que, aún muy diferentes a los míos, respondan a una misma finalidad: reforzar la acción de Eros a expensas de Tánatos, hacer más fácil el acceso al derecho y al placer de pensar, de disfrutar, de existir......"

\section{REFERENCIAS}

Baranger, W., Goldstein, N. y Zak de Goldstein, R. (1994) Artesanías Psicoanalíticas. Buenos Aires: Kargieman.

Bion, W. R. (1962). Aprendiendo de la Experiencia. Buenos Aires: Paidós.

Castoriadis-Aulagnier, P. (1988a) La violencia de la interpretación. Del pictograma al enunciado. Buenos Aires: Amorrortu Editores.

Castoriadis-Aulagnier, P. (1992b) El aprendiz de historiador y el maestro- brujo. Buenos Aires: Amorrortu Editores.

Freud, S. (1900a) La interpretación de los sueños. O.C. Tomo IV y V, Buenos Aires: Amorrortu Editores.

Freud, S. (1905b) Tres ensayos de teoría sexual. O.C. Tomo VII, Buenos Aires: Amorrortu Editores.

Freud, S. (1905c) El chiste y su relación con lo inconsciente. O.C. Tomo VIII, Buenos Aires: Amorrortu Editores.

Freud, S. (1912d) Consejos al médico sobre el tratamiento psicoanalítico. O.C. Tomo XII, Buenos
Aires: Amorrortu Editores.

Freud, S. (1912e) Sobre la dinámica de la transferencia. O.C. Tomo XII, Buenos Aires: Amorrortu Editores.

Freud, S. (1913f) Sobre la iniciación del tratamiento. O.C. Tomo XII, Buenos Aires: Amorrortu Editores.

Freud, S. (1914) Sobre la iniciación del tratamiento. O.C. Tomo XII, Buenos Aires: Amorrortu Editores.

Freud, S. (1915h) La represión, O.C. Tomo XIV, Buenos Aires: Amorrortu Editores.

Freud, S. (1919 a,i) Nuevos caminos de la terapia psicoanalítica. O.C. Tomo XVII, Buenos Aires: Amorrortu Editores.

Freud, S. (1921j) Psicología de las masas y análisis del yo. O.C. Tomo XVIII, Buenos Aires: Amorrortu Editores.

Freud, S. (1922k) Sobre algunos mecanismos neuróticos en los celos, la paranoia y la homosexualidad. O.C. Tomo XVIII, Buenos Aires: Amorrortu Editores.

Lacan J. (1960) Subversión del sujeto y dialéctica del deseo en el inconsciente freudiano. Escritos 2. México: Siglo XXI editores.

Laplanche, J. (1987a) La cubeta. Trascendencia de la Transferencia. Buenos Aires: Amorrortu Editores.

Laplanche, J. (1992b) La prioridad del otro en Psicoanálisis. Buenos Aires: Amorrortu Editores.

Laplanche, J. y Pontalis, JB (1981c). Diccionario de Psicoanálisis. Barcelona: Ed. Labor.

Paniagua, C. (2004) Algunos comentarios críticos sobre la intersubjetividad. En Glocer Fiorini, L. (Compiladora, APA). El otro en la trama intersubjetiva. Buenos Aires: Lugar. 